\title{
A NEW APPROACH FOR RANKING SHADOWED FUZZY NUMBERS AND ITS APPLICATION
}

\author{
Mohamed A. H. El-Hawy \\ Department of Management Information Systems, Modern Academy for \\ Computer Science and Management Technology, Cairo, Egypt
}

\begin{abstract}
In many decision situations, decision-makers face a kind of complex problems. In these decision-making problems, different types of fuzzy numbers are defined and, have multiple types of membership functions. So, we need a standard form to formulate uncertain numbers in the problem. Shadowed fuzzy numbers are considered granule numbers which approximate different types and different forms of fuzzy numbers. In this paper, a new ranking approach for shadowed fuzzy numbers is developed using value, ambiguity and fuzziness for shadowed fuzzy numbers. The new ranking method has been compared with other existing approaches through numerical examples. Also, the new method is applied to a hybrid multi-attribute decision making problem in which the evaluations of alternatives are expressed with different types of uncertain numbers. The comparative study for the results of different examples illustrates the reliability of the new method.
\end{abstract}

\section{KEYWORDS}

Fuzzy numbers, Intuitionistic fuzzy numbers, Shadowed sets, Shadowed fuzzy numbers, Ranking, Fuzziness measure.

\section{INTRODUCTION}

Vague information is represented by many uncertain sets. Fuzzy set is one of the most important uncertain set which was proposed by Zadeh. Fuzzy set is determined by its membership function that represents vagueness and imprecision in linguistic term. fuzzy number is a special type of fuzzy set which is defined on real numbers scale.

Intuitionistic fuzzy sets (IFSs) are introduced by Atanassov which generalized the concept of fuzzy set. IFSs are characterized by two functions (membership and non-membership) [1]. These features provide more flexibility in representing uncertain numbers. The shadowed sets proposed by Pedrycz for approximation of fuzzy sets by three values $\{0,1,[0,1]\}[2]$. Fuzzy membership values assign to 0,1 or uncertain interval. Three areas are induced from fuzzy set to define shadowed set. The elements with membership grade 0 constitute the excluded area of the shadowed set. The core area consists of the elements that almost certainly belong to the fuzzy set. The shadow area relates to the elements that possibly belong to the fuzzy set.

The author proposed an improved form of shadowed fuzzy numbers (SFNs) which preserves two types of uncertainty (fuzziness and non-specificity) [3]. Also, we extended this idea to a higher type of fuzzy sets [4].

In the literature, numerous ranking approaches have been developed to rank fuzzy numbers. One category of these methods ranks fuzzy numbers based on the integration between fuzzy mean and 
spread. The mean of fuzzy number is represented generally as the centroid value of it. The spread of fuzzy numbers is used to support ranking methods, especially in the cases of embedded fuzzy numbers with different spreads [5]. Many researchers have dealt with the issue of ranking fuzzy numbers using centroid point and spread $[6,7,8,9]$. Chen and Lu presented the ranking method for fuzzy numbers which consider the middle-point and spread of each $\alpha$-cut of fuzzy numbers [10]. Abu Bakar et al. proposed ranking method using five distance-based components for ranking fuzzy numbers that include centroid point, height and spread of fuzzy numbers [11]. S.M. Chen and J.H. Chen presented a new ranking method based on the defuzzified values, the heights and the spreads for generalized fuzzy numbers [12]. Abu Bakar et al. proposed a ranking index which integrates centroid point and spread for fuzzy numbers [13]. R. Chutia and B. Chutia discussed the concept of parametric form of fuzzy number and proposed a new ranking method using the value and the ambiguity of it at different decision levels [14]. The same concept of the integration between value and ambiguity is applied on intuitionistic fuzzy numbers IFNs. DengFeng Li developed a new methodology for ranking triangular Intuitionistic fuzzy numbers TIFNs based on a ratio of the value index to the ambiguity index and applied to multi-attribute decision making problem [15]. P. K. De and D. Das proposed a new ranking approach for trapezoidal intuitionistic fuzzy numbers (TrIFN) using the value and the ambiguity indexes of them [16]. Some ranking methods provide ability to rank different types of fuzzy numbers using value and ambiguity. Also, other approaches are intended for one type of fuzzy numbers or one kind of membership functions. Some researchers proposed ranking method has related to the fuzziness of fuzzy numbers [17]. In this paper, a new method for ranking shadowed fuzzy numbers is proposed to order different types of fuzzy numbers and different membership functions. The value and ambiguity of a shadowed fuzzy number SFN will be defined. The proposed method uses values and ambiguities of SFNs to rank them. Also, the fuzziness values of SFNs are used to support ranking approach in the case of the equality of ranking values and ambiguities. The proposed ranking approach will be presented and applying to different fuzzy numbers ranking examples. Also, the new algorithm is proposed to solve a hybrid multi-attribute decision making problem that includes the new SFNs ranking approach. This MADM problem has different data types include interval numbers, type-1 fuzzy numbers with two different membership function types and intuitionistic fuzzy numbers. The reset of this paper is organized as follows: section 2 introduces the basic definitions of FNs, IFNs and SFNs. Section 3 defines the concepts of the value, the ambiguity and the fuzziness of SFNs. we introduce proposed steps for new ranking method of SFNs. Section 4, numerical examples are provided, and a comparative study is presented with previous methods. Also, we present a hybrid multi-attribute decision making problem which is solved by using the proposed algorithm. Finally, conclusions and the main features of the proposed ranking approach are discussed in Section 5.

\section{Definitions ANd Preliminaries}

\subsection{Fuzzy Sets}

Fuzzy set provides excellent means to model the linguistic terms by introducing gradual memberships. The membership function of a fuzzy set A is defined as follows [18]

$$
A: X \rightarrow[0,1]
$$

The membership function mapping elements of universe of discourse $X$ to unit interval $[0,1]$. The membership function is essential for describing fuzzy set. 


\subsubsection{Fuzzy Number}

A fuzzy number (FN) $\widetilde{A}$ is a fuzzy set that is defined on the real numbers scale $\mathbb{R}$ with the following conditions $[19,20]$.

- $\widetilde{\mathrm{A}}$ is normal, i.e. at least one element $\mathrm{x}_{\mathrm{i}}$ such that $\mu\left(\mathrm{x}_{\mathrm{i}}\right)=1$.

- $\widetilde{\mathrm{A}}$ is a convex such that $\widetilde{\mathrm{A}}(\delta \mathrm{x}+(1-\delta) \mathrm{y}) \geq \min (\widetilde{\mathrm{A}}(\mathrm{x}),(\mathrm{y})) \forall \mathrm{x}, \mathrm{y} \in \mathrm{U}$ and $\delta \in[0,1]$ where $U$ is a universe of discourse.

- $\quad$ The support of $\widetilde{\mathrm{A}}$ is bounded.

A fuzzy number is important to approximate uncertainty concept about numbers or intervals. The membership function of the real fuzzy number $\widetilde{\mathrm{A}}$ is defined by [19]

$$
\mu_{\widetilde{A}}(x)=\left\{\begin{array}{cc}
l_{\widetilde{A}}(x) & \text { if } a \leq x \leq b \\
1 & \text { if } b \leq x \leq c \\
r_{\widetilde{A}}(x) & \text { if } c \leq x \leq d \\
0 & \text { otherwise }
\end{array}\right.
$$

where $\mathrm{l}_{\widetilde{\mathrm{A}}}$ and $\mathrm{r}_{\widetilde{\mathrm{A}}}$ are two continuous increasing and decreasing functions for left and right side of fuzzy number, $x \in U$ and $a, b, c, d$ are real numbers.

\subsection{Intuitionistic Fuzzy Sets}

The concept of intuitionistic fuzzy sets (IFS) is introduced in 1986 by Atanassov. This concept is defined with membership function and non-membership function $[1,21]$. Let $A$ is an intuitionistic fuzzy set in finite set $X$ and is defined as

$$
A=\left\{<x, \mu_{\mathrm{A}}(\mathrm{x}), \mathrm{v}_{\mathrm{A}}(\mathrm{x})>\mid \mathrm{x} \in X\right\}
$$

Where $\mu_{A}(x): X \rightarrow[0,1]$ is the membership function of $A, v_{A}(x): X \rightarrow[0,1]$ is the nonmembership function of $A$, such that

$$
0 \leq \mu_{\mathrm{A}}(\mathrm{x})+\mathrm{v}_{\mathrm{A}}(\mathrm{x}) \leq 1
$$

For each intuitionistic fuzzy set in $\mathrm{X}$, the intuitionistic index of $\mathrm{x}$ in $\mathrm{A}$ or a hesitancy degree of $\mathrm{x}$ to $\mathrm{A}$ is defined as

$$
\pi_{\mathrm{A}}=1-\mu_{\mathrm{A}}(\mathrm{x})-\mathrm{v}_{\mathrm{A}}(\mathrm{x})
$$

Where $0 \leq \pi_{\mathrm{A}} \leq 1$. For each $\mathrm{x} \in \mathrm{X}$

\subsubsection{Intuitionistic Fuzzy Numbers (IFN)}

An intuitionistic fuzzy subset is called an intuitionistic fuzzy number, if it's defined on real numbers domain as $[22,23]$

$$
\mathrm{A}=\left\{<x, \mu_{\mathrm{A}}(\mathrm{x}), \mathrm{v}_{\mathrm{A}}(\mathrm{x})>\mid \mathrm{x} \in \mathbb{R}\right\}
$$

Where 
1. A is normal, i.e. at least two points $x_{0}, x_{1}$ belong to $A$ such that $\mu_{A}\left(x_{0}\right)=1, v_{A}\left(x_{1}\right)=1$.

2. A is convex, i.e. $\mu_{A}$ is fuzzy convex and $v_{A}$ is fuzzy concave.

3. $\mu_{A}$ is upper semicontinuous and $v_{A}$ is lower semicontinuous.

4. $\operatorname{support}(\mathrm{A})=\left\{\mathrm{x} \in \mathrm{X} \mid v_{A}(\mathrm{x})<1\right\}$ is bounded.

\subsection{Shadowed Sets}

In this section, we present some basic concepts of shadowed sets. The shadowed set $\mathrm{S}$ is defined by a mapping from a universal set $\mathrm{X}$ to the set of three values as [2, 24, 25]

$$
S: X \rightarrow\{0,1,[0,1]\}
$$

Shadowed set is created by optimization of the threshold $\alpha$ that is calculated using the objective function as

$$
\mathrm{v}\left(\mathrm{r}_{1}\right)+\mathrm{v}\left(\mathrm{r}_{2}\right)=\mathrm{v}\left(\mathrm{r}_{3}\right)
$$

where $\mathrm{v}$ is uncertainty of regions $\mathrm{r}_{1}, \mathrm{r}_{2}, \mathrm{r}_{3}$. The $\mathrm{r}_{1}$ region is induced by reduce all membership values less than the threshold $\alpha$ to 0 . The $r_{2}$ region is created by elevated membership values more than 1- $\alpha$ to 1 . The $r_{3}$ is a shadow region for membership values around 0.5 as illustrated in Figure 1.

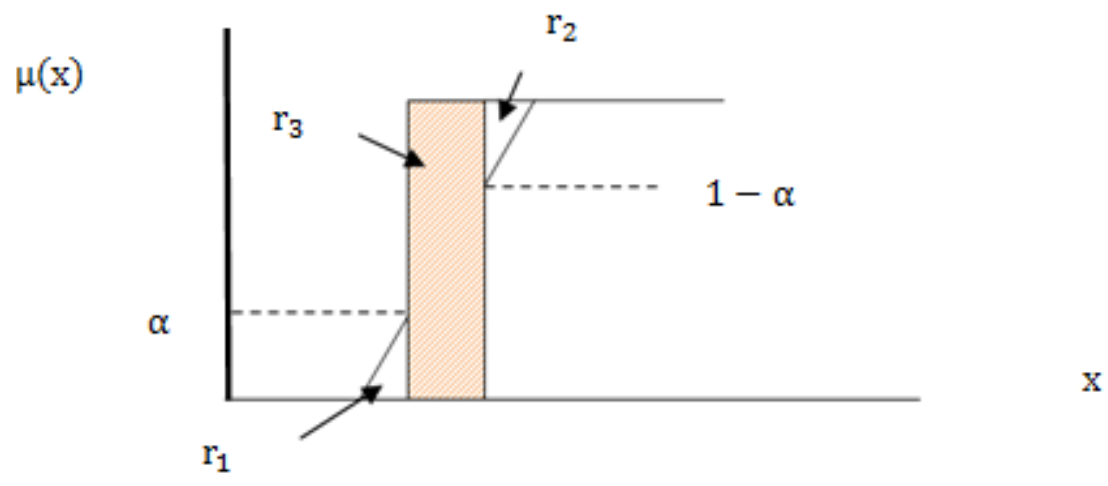

Figure 1: Regions that construct shadowed set

The optimal $\alpha$ can be derived by minimizing the objective function which achieves the balance of uncertainty with these regions as the following

$$
\mathrm{V}_{\alpha}=\left|\mathrm{v}\left(\mathrm{r}_{1}\right)+\mathrm{v}\left(\mathrm{r}_{2}\right)-\mathrm{v}\left(\mathrm{r}_{3}\right)\right|
$$

where $V_{\alpha}$ is the performance index for the threshold $\alpha$ and $\alpha \in[0,0.5)$. Pedrycz calculated optimum $\alpha$ for triangular, Gaussian and parabolic fuzzy sets to be $0.4142,0.395$ and 0.405 respectively.

\subsubsection{Shadowed Fuzzy Numbers}

Shadowed fuzzy numbers (SFNs) are induced from fuzzy numbers [26]. The author proposed an improved approach to create SFN that preserves uncertainty characteristics of fuzzy number and can be deduced from type-1 fuzzy numbers and higher type of them e.g., intuitionistic fuzzy sets (IFS) [4]. The author method is deduced SFN by building core interval and fuzziness intervals as 
in Figure 4 [23]. In the case of type-1 fuzzy numbers, the $\alpha$-core can be derived using the following equation [3]

$$
A_{R}(\alpha)-A_{L}(\alpha)+1=2^{H_{A}}
$$

where $H_{A}$ is the non-specificity value of fuzzy set $A[27,23] . A_{L}(\alpha)$ and $A_{R}(\alpha)$ are left and right $\alpha$-cut functions of fuzzy number A. The $\alpha$-core interval illustrates in Figure 2.
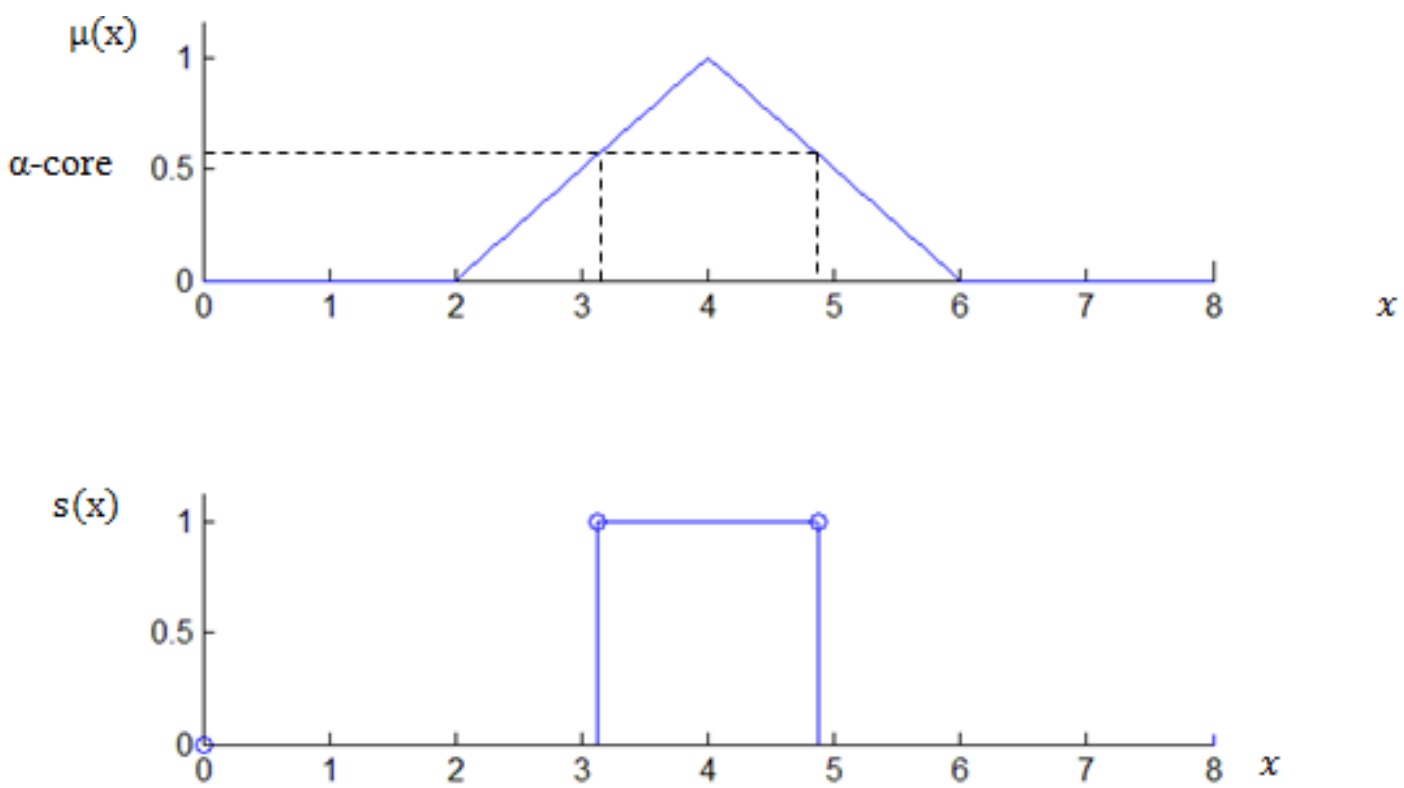

Figure 2: core interval for triangular fuzzy number

The shadow intervals represent fuzziness of fuzzy sets and are calculated for type-1 fuzzy number as

$$
\begin{aligned}
& \mathrm{w}_{\mathrm{L}}=\sum_{\mathrm{x}_{\mathrm{L}}} \mathrm{f}_{\mathrm{A}}\left(\mathrm{x}_{\mathrm{L}}\right) \\
& \mathrm{w}_{\mathrm{R}}=\sum_{\mathrm{x}_{\mathrm{R}}} \mathrm{f}_{\mathrm{A}}\left(\mathrm{x}_{\mathrm{R}}\right)
\end{aligned}
$$

where $\mathrm{x}_{\mathrm{L}}$ and $\mathrm{x}_{\mathrm{R}}$ are respectively the left support and right support of fuzzy number $\mathrm{A}$ from core value. $w_{L} a n d w_{R}$, are the left and right fuzziness intervals. The fuzziness intervals represent uncertainty regions. $f_{A}$ is the fuzziness set of fuzzy number A as in Figure 3. It is proposed by Tahayori and is defined as the following [28]

$$
\begin{gathered}
f_{A}=(x, \operatorname{fuzz}(x)), \\
\operatorname{fuzz}(x)=1-\left|2 \mu_{A}(x)-1\right| .
\end{gathered}
$$


$\mu(\mathrm{x})$

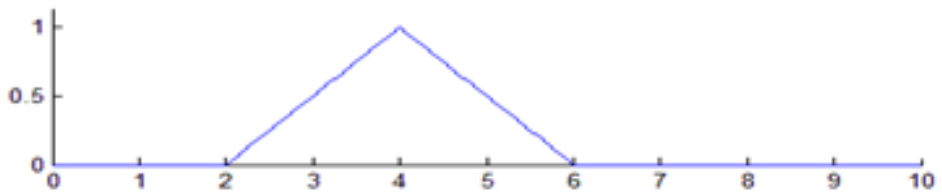

$f(x)$

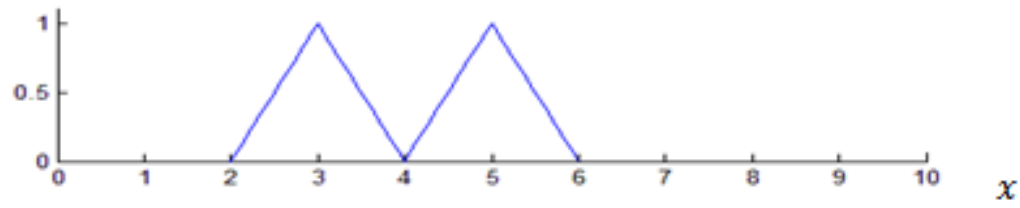

Figure 3: Fuzziness set for a triangular fuzzy set

$\mu(\mathrm{x})$

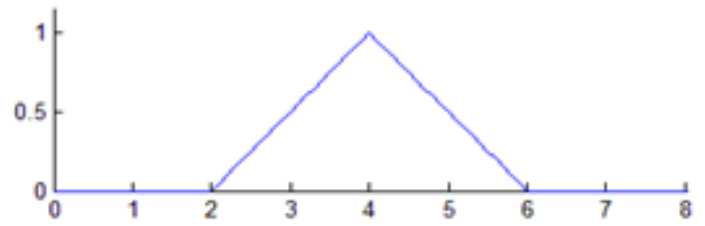

$x$

$\mathrm{S}(\mathrm{x})$

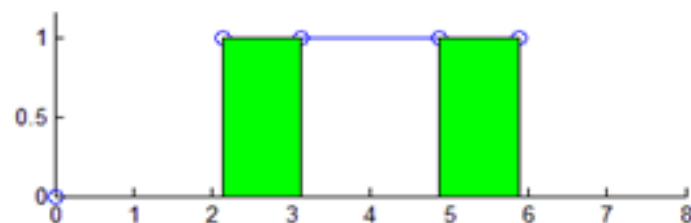

Fuzziness
interval

$\square$ Core interval

Figure 4: The SFN for triangular fuzzy number

\section{The Proposed Method FOR RANKIng SFNS}

In this section, we present a new approach for ranking shadowed fuzzy numbers (SFNs). This method is used to order fuzzy numbers that SFNs are induced from them. Our proposed method is based on new concepts of SFN namely the value and the ambiguity of SFN. These concepts will be proposed based on Delgado et al. definitions of the value and the ambiguity [29].

\section{Definition 3.1:}

Let us consider SFN $S_{A}$ that parameterizes as the following

$\mathrm{S}_{\mathrm{A}}=\left(\mathrm{s}_{1}^{\mathrm{A}}, \mathrm{s}_{2}^{\mathrm{A}}, \mathrm{s}_{3}^{\mathrm{A}}, \mathrm{s}_{4}^{\mathrm{A}}\right)$ then $\mathrm{C}_{\mathrm{A}}=\left(\mathrm{s}_{2}^{\mathrm{A}}, \mathrm{s}_{3}^{\mathrm{A}}\right)$ is the core interval of $\mathrm{S}_{\mathrm{A}}$. Also, let $\mathrm{F}_{\mathrm{S}}^{\mathrm{A}}$ is the fuzziness value of $S_{A}$ such that [18]

$$
\mathrm{F}_{\mathrm{S}}^{\mathrm{A}}=\left(\mathrm{s}_{2}^{\mathrm{A}}-\mathrm{s}_{1}^{\mathrm{A}}\right)+\left(\mathrm{s}_{4}^{\mathrm{A}}-\mathrm{s}_{3}^{\mathrm{A}}\right)
$$

\section{Definition 3.2:}

Let $V_{S}^{A}$ is the value of the SFN $S_{A}$ and is defined as 
International Journal of Computer Science \& Information Technology (IJCSIT) Vol 12, No 6, December 2020

$$
\mathrm{V}_{\mathrm{S}}^{\mathrm{A}}=\frac{\left(\mathrm{s}_{2}^{\mathrm{A}}+\mathrm{s}_{3}^{\mathrm{A}}\right)}{2}
$$

\section{Definition 3.3:}

Let $S_{A}$ is the SFN which induced from fuzzy number $A$. Then the ambiguity value $u_{S}^{A}$ of $S_{A}$ is defined as

$$
\mathrm{u}_{\mathrm{S}}^{\mathrm{A}}=\mathrm{s}_{3}^{\mathrm{A}}-\mathrm{s}_{2}^{\mathrm{A}}
$$

\section{Definition 3.4:}

Let $S_{A}$ and $S_{B}$ are two SFNs which induced from fuzzy numbers $A$ and $B$. Let $A m b_{S}^{A}$ and $A m b_{S}^{B}$ are the ambiguity indexes for $S_{A}$ and $S_{B}$ respectively and are defined as

$$
\mathrm{Amb}_{\mathrm{S}}^{\mathrm{A}}=1-\frac{\mathrm{u}_{\mathrm{S}}^{\mathrm{A}}}{\mathrm{u}_{\mathrm{S}}^{\mathrm{A}}+\mathrm{u}_{\mathrm{S}}^{\mathrm{B}}}
$$

and

$$
A m b_{S}^{B}=1-\frac{u_{S}^{B}}{u_{S}^{A}+u_{S}^{B}}
$$

where $u_{S}^{A}$ and $u_{S}^{B}$ are ambiguity values for $S_{A}$ and $S_{B}$ respectively

\section{Definition 3.5:}

Let $S_{A}$ is the $S F N$ which induced from fuzzy number $A$. Then the rank value $R_{S}^{A}$ of $S_{A}$ is defined as

$$
\mathrm{R}_{\mathrm{S}}^{\mathrm{A}}=\mathrm{V}_{\mathrm{S}}^{\mathrm{A}}+\mathrm{Amb}_{\mathrm{S}}^{\mathrm{A}} \times \lambda
$$

where $V_{S}^{A}$ is the value of $S_{A}, A m b_{S}^{A}$ is the ambiguity index of $S_{A}$ and $\lambda$ is an attitude value (AV) where $\lambda \in[0.5,1]$

An attitude value (AV) represents the attitude of the decision maker against ambiguity. In the case of $\lambda=1$, this value indicates a decision maker's optimistic attitude towards ambiguity. If $\lambda \in] 0.5,1$ [ then AV refers to decision maker's neutral attitude towards ambiguity. When $\lambda=$ 0.5 , this value indicates decision maker's pessimistic attitude towards ambiguity. In rank examples, we prefer to $\lambda=0.5$ which more reasonable.

\section{A ranking procedure of two SFNs $S_{A}$ and $S_{B}$, as the following steps:}

Step 1: Calculate $V_{S}^{A}, V_{S}^{B}, A m b_{S}^{A}$ and $A m b_{S}^{B}$ for $S_{A}$ and $S_{B}$ using (16), (17), (18) and (19).

Step 2: Calculate rank values for $S_{A}$ and $S_{B}$ with an attitude value (AV) $\lambda$ and $\lambda \in[0.5,1]$ using (20). 
Step 3: the ranking of two SFNs is according to

If $\mathrm{R}_{\mathrm{S}}^{\mathrm{A}}>\mathrm{R}_{\mathrm{S}}^{\mathrm{B}}$ then $\mathrm{S}_{\mathrm{A}}>\mathrm{S}_{\mathrm{B}}$ and $\mathrm{A}>B$.

If $\mathrm{R}_{\mathrm{S}}^{\mathrm{A}}<\mathrm{R}_{\mathrm{S}}^{\mathrm{B}}$ then $\mathrm{S}_{\mathrm{A}}<\mathrm{S}_{\mathrm{B}}$ and $\mathrm{A}<B$.

If $R_{S}^{A}=R_{S}^{B}$ then calculate $F_{S}^{A}$ and $F_{S}^{B}$ of two SFNs $S_{A}$ and $S_{B}$ using (15) and

If $\mathrm{F}_{\mathrm{S}}^{\mathrm{A}}<\mathrm{F}_{\mathrm{S}}^{\mathrm{B}}$ then $\mathrm{S}_{\mathrm{A}}>\mathrm{S}_{\mathrm{B}}$ and $\mathrm{A}>B$

If $\mathrm{F}_{\mathrm{S}}^{\mathrm{A}}>\mathrm{F}_{\mathrm{S}}^{\mathrm{B}}$ then $\mathrm{S}_{\mathrm{A}}<\mathrm{S}_{\mathrm{B}}$ and $\mathrm{A}<B$

If $\mathrm{F}_{\mathrm{S}}^{\mathrm{A}}=\mathrm{F}_{\mathrm{S}}^{\mathrm{B}}$ then $\mathrm{S}_{\mathrm{A}}=\mathrm{S}_{\mathrm{B}}$ and $\mathrm{A}=\mathrm{B}$

\section{NUMERICAL EXAMPLES}

In this section, five numerical examples are used to demonstrate the new proposed method reliability for ranking the fuzzy numbers. The proposed method is compared with other existing ranking methods that integrate the centroid point and the spread of fuzzy numbers. Also, the comparison extends to other methods that have ordered fuzzy numbers using their values and ambiguities. This comparative study is summarized in Table 1. A new additional example will be presented in this section to illustrate the characteristic of the new method for ranking different types of IFNs. Also, a hybrid multi-attribute decision making problem will be solved using the new approach.

Example 1: Let $A$ and $B$ are two triangular fuzzy numbers TFNs such that $A=(0.1,0.4,0.7)$ and $B=(0.3,0.4,0.5)$ as in Figure 5. Using our method, Two SFNs $S_{A}$ and $S_{B}$ are induced from two fuzzy numbers $A$ and $B$ such that $S_{A}=(0.1,0.25,0.55,0.7)$ and $S_{B}=(0.3,0.35,0.45,0.5)$ [23]. We use (20) to obtain the rank values of $S_{A}$ and $S_{B}$ using $\lambda=0.5$ as the following:

$R_{A}=0.525$ and $R_{B}=0.775$. Based on these results, the ranking of fuzzy numbers is $A<B$.

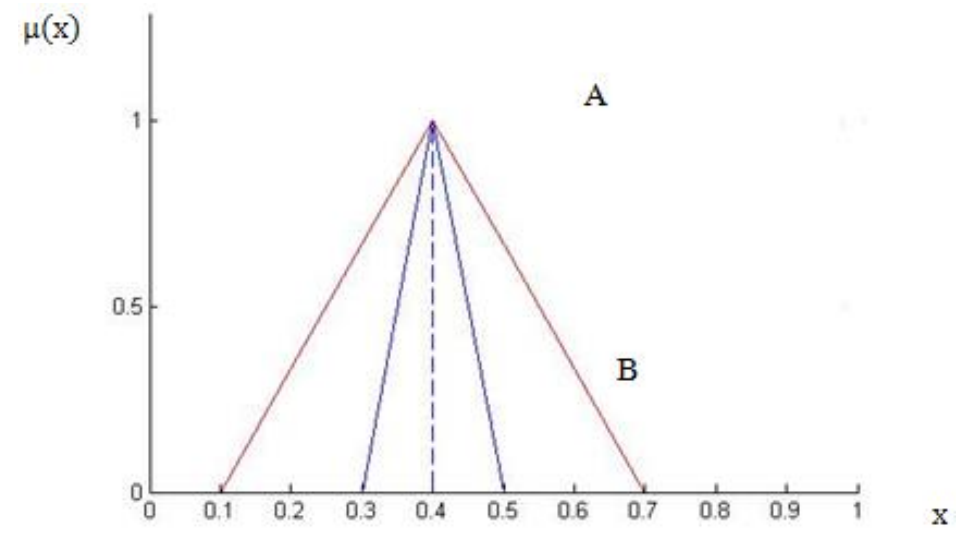

\section{Example 2:}

Figure 5: Fuzzy numbers A and B of Example 1

Let $\mathrm{A}$ is a trapezoidal fuzzy number $\operatorname{TrFN}$ and $\mathrm{B}$ is a triangular fuzzy numbers TFN such that $\mathrm{A}=$ $(0.1,0.2,0.4,0.5)$ and $\mathrm{B}=(0.1,0.3,0.5)$ as in Figure 6.

Using the author method, two SFNs $S_{A}$ and $S_{B}$ are obtained from two FNs A and B such that $\mathrm{S}_{\mathrm{A}}=$ $(0.1,0.15,0.45,0.5)$ and $S_{B}=(0.1,0.2,0.4,0.5)$ [3]. The rank values for $S_{A}$ and $S_{B}$ are calculated with $\lambda=0.5$ and the results are $R_{A}=0.5$ and $R_{B}=0.6$. The order of fuzzy numbers is $\mathrm{A}<\mathrm{B}$. 
$\mu(\mathrm{x})$

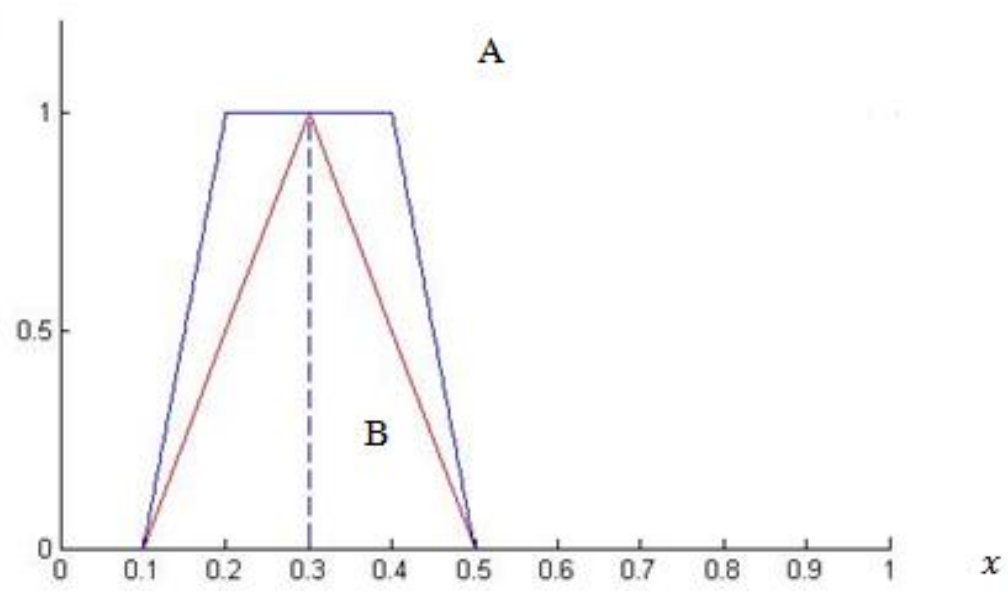

Figure 6: Fuzzy numbers A and B of Example 2

\section{Example 3:}

Consider the following two fuzzy numbers with different heights as shown in Figure 7. $\mathrm{A}=(0.1,0.4,0.7)$ and height $(\mathrm{A})=0.8, \mathrm{~B}=(0.1,0.4,0.7)$ and height $(\mathrm{B})=1$

Using the same calculation steps as the previous examples, we get $\mathrm{S}_{\mathrm{A}}=\left(\begin{array}{lll}0.08 & 0.2538 & 0.5462\end{array}\right.$ $0.72) ; \mathrm{S}_{\mathrm{B}}=(0.1038,0.2538,0.5462,0.6962) ; \mathrm{R}_{\mathrm{A}}=0.65 ; \mathrm{R}_{\mathrm{B}}=0.65$.

Based on these results, the two ranking values are equal so, we use (15) to obtain fuzziness values for each SFN. The fuzziness values are $F_{S}^{A}=0.345$ and $F_{S}^{B}=0.3$ then the ranking of fuzzy numbers is $\mathrm{A}<\mathrm{B}$.

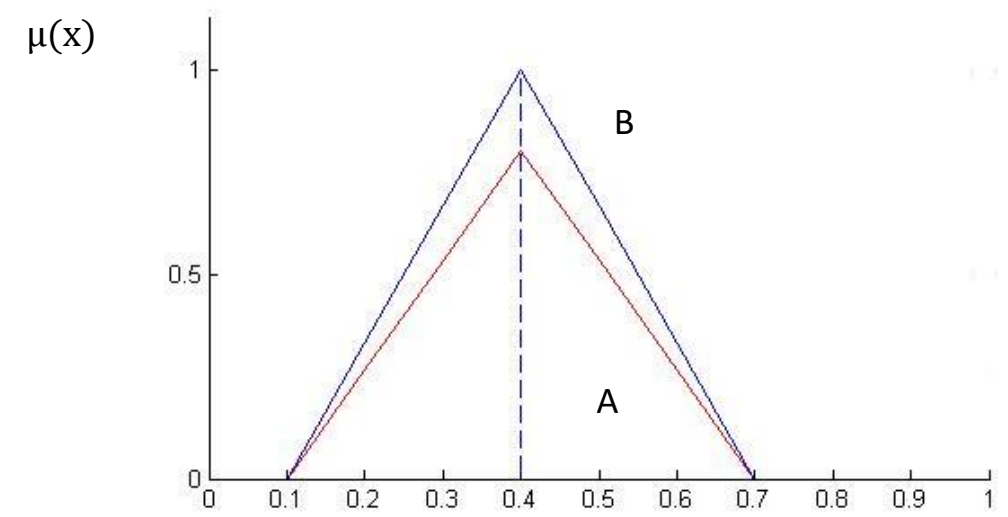

\section{Example 4:}

Figure 7: Fuzzy numbers A and B of Example 3

Let $\mathrm{A}$ and $\mathrm{C}$ are TrFNs and $\mathrm{B}$ is TFN such that $\mathrm{A}=(0,0.4,0.6,0.8), \mathrm{B}=(0.2,0.5,0.9)$ and $\mathrm{C}=$ $(0.1,0.6,0.7,0.8)$, as in Figure 8.

Using the author method, we induce three SFNs where $S_{A}=(0.0034,0.2034,0.6983,0.7983)$, $\mathrm{S}_{\mathrm{B}}=(0.2052,0.3552,0.6931,0.8931)$ and $\mathrm{S}_{\mathrm{C}}=(0.1124,0.3624,0.7475,0.7975)[3]$. We use (20) to obtain the rank values for $S_{A}, S_{B}$ and $S_{C}$ using $\lambda=0.5$ as the following: 
$\mathrm{R}_{\mathrm{A}}=0.7477, \mathrm{R}_{\mathrm{B}}=0.8854$ and $\mathrm{R}_{\mathrm{C}}=0.8968$. According to these results, the ranking of fuzzy numbers is $\mathrm{A}<\mathrm{B}<C$.

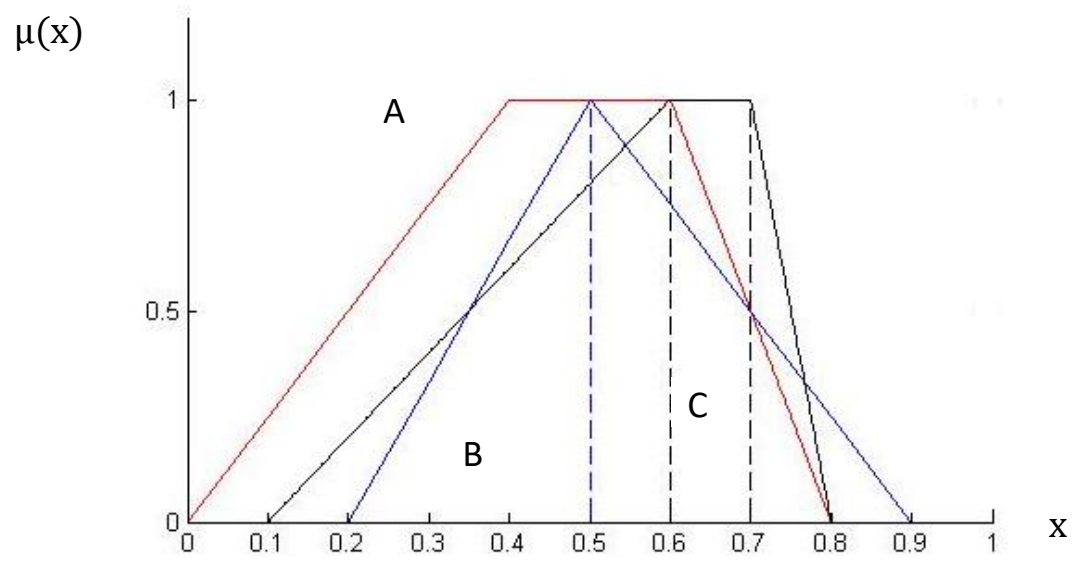

Figure 8: Fuzzy numbers A, B and C of Example 4

Table 1: Comparative results of the proposed ranking method with the existing ranking methods

\begin{tabular}{|c|c|c|c|c|}
\hline Examples & $\begin{array}{c}\text { Chen and Sanguansat } \\
{[5]}\end{array}$ & $\begin{array}{c}\text { Abu Bakar and } \\
\text { Gegov [13] }\end{array}$ & $\begin{array}{c}\text { R.Chutia and } \\
\text { B.Chutia [14] }\end{array}$ & Proposed method \\
\hline 1 & $\mathrm{~A} \approx \mathrm{B}$ & $\mathrm{A}>B$ & $\mathrm{~A}<\mathrm{B}$ & $\mathrm{A}<\mathrm{B}$ \\
\hline 2 & $\mathrm{~A} \approx \mathrm{B}$ & $\mathrm{A}>B$ & $\mathrm{~A}<\mathrm{B}$ & $\mathrm{A}<\mathrm{B}$ \\
\hline 3 & $\mathrm{~A}<\mathrm{B}$ & $\mathrm{A}<\mathrm{B}$ & $\mathrm{A}<\mathrm{B}$ & $\mathrm{A}<\mathrm{B}$ \\
\hline 4 & $\mathrm{~A}<\mathrm{B}<\mathrm{C}$ & $\mathrm{A}<\mathrm{B}<C$ & $\mathrm{~A}<\mathrm{B}<C$ & $\mathrm{~A}<\mathrm{B}<C$ \\
\hline
\end{tabular}

\section{Example 5:}

Let $A_{1}, A_{2}$ and $A_{3}$ are three trapezoidal intuitionistic fuzzy numbers (TrIFNs), where $A_{1}=$ $[(0.1,0.3,0.5,0.8),(0.1,0.3,0.5,0.8) 0.5,0.2], \mathrm{A}_{2}=[(0.2,0.3,0.6,0.9),(0.2,0.3,0.6,0.9) 0.6,0.4]$ and $\mathrm{A}_{3}=[(0.1,0.5,0.7,0.9),(0.1,0.5,0.7,0.9) 0.5,0.3]$ [16]. We induce three SFNs using author method such that $\mathrm{S}_{\mathrm{A}_{1}}=(0.15,0.27,0.54,0.725), \mathrm{S}_{\mathrm{A}_{2}}=(0.23,0.29,0.64,0.81)$ and $\mathrm{S}_{\mathrm{A}_{3}}=(0.23$, $0.47,0.71,0.83$ )[4]. The rank values of $\mathrm{S}_{\mathrm{A}_{1}}, \mathrm{~S}_{\mathrm{A}_{2}}$ and $\mathrm{S}_{\mathrm{A}_{3}}$ are calculated by using (20) with $\lambda=$ 0.5 and the results are $\mathrm{R}_{\mathrm{A}_{1}}=0.748, \mathrm{R}_{\mathrm{A}_{2}}=0.7615$ and $\mathrm{R}_{\mathrm{A}_{3}}=0.9505$. According to these results, the order of three TrIFNs is $A_{1}<A_{2}<A_{3}$.

\section{Example 6:}

In this example, we apply the proposed method on the case of ranking three different types of intuitionistic fuzzy numbers.

Let $B_{1}, B_{2}$ and $B_{3}$ are three different types of intuitionistic fuzzy numbers(IFNs), where $B_{1}=$ $[(2,3,5,6),(1,3,5,7) 1,0]$ is trapezoidal intuitionistic fuzzy number(TrIFN), $B_{2}=[(m=4, \sigma=0.5)$ $,(\mathrm{m}=4, \sigma=1) 1,0]$ is Gaussian intuitionistic fuzzy number(GIFN), and $\mathrm{B}_{3}=[(3,6,9),(4,6,8) 1,0]$ is triangular intuitionistic fuzzy numbers (TIFN) as in Figure 9. Three SFNs are induced using authors method as $S_{1}=[1.615,2.31,5.7,6.386], S_{2}=[2.12,3.17,4.83,5.88]$ and $S_{3}=[3.653$, 4.93, 7.07, 8.35][4]. Using the new ranking method, The rank values of $S_{1}, S_{2}$ and $S_{3}$ are $R_{1}=$ $4.2693, R_{2}=4.3846$ and $R_{3}=6.3512$ with $\lambda=0.5$ then the order of SFNs is $S_{3}>S_{2}>S_{1}$. According to this result, the ranking for three IFNs is $B_{3}>B_{2}>B_{1}$. 


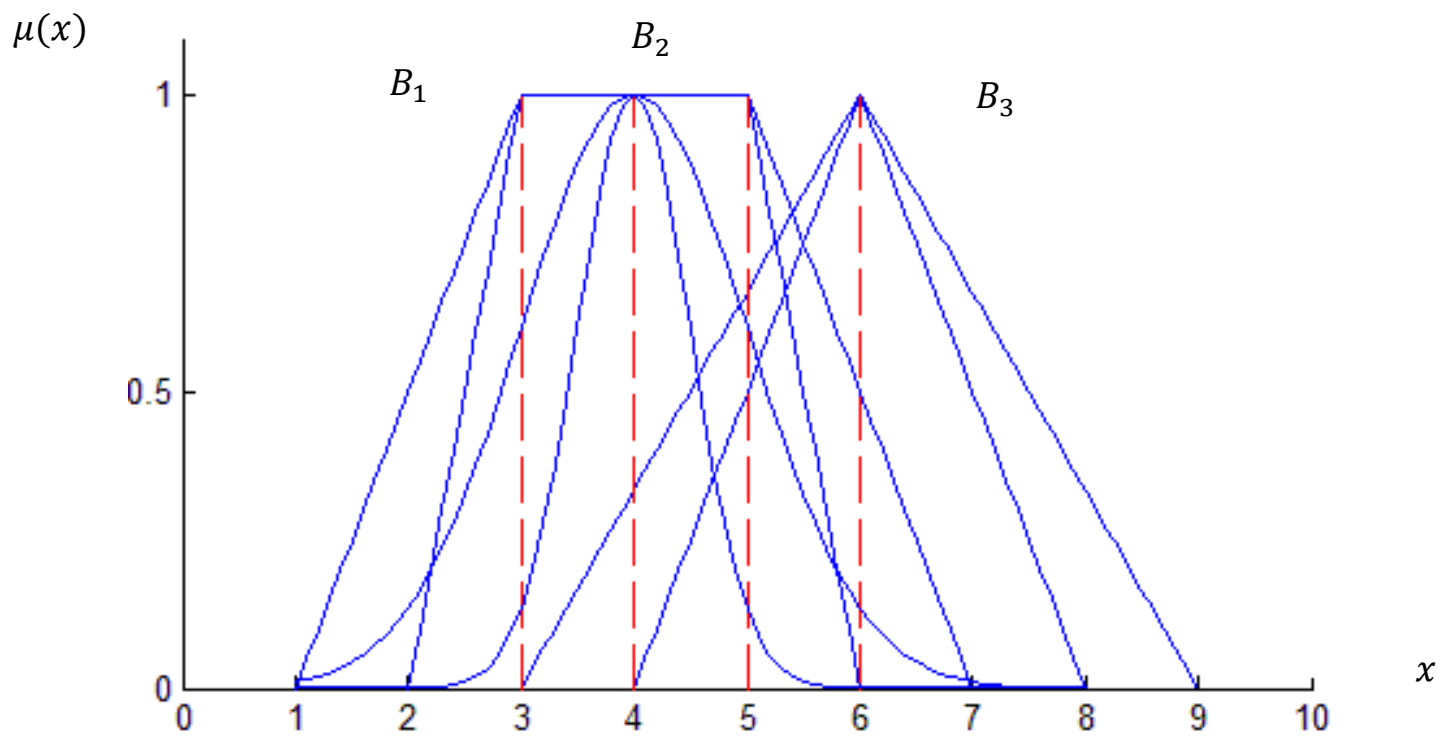

Figure 9: Three IFNs $B_{1}, B_{2}$ and $B_{3}$

\subsection{Discussion of the Results of Examples}

1. For the fuzzy numbers A and B as in the example 1, Chen and Sanguansat method fail to discriminate between two fuzzy numbers which they have the same value as in Table 1 . Abu Baker and Gegov method prefers fuzzy number A to B but the ambiguity of B is less than A. R.Chutia and B.Chutia method and the proposed method get the same ranking order, which is consistent with intuition. The two fuzzy numbers have the same value, but they are different in ambiguities.

2. In the example 2, the correct ranking order of fuzzy numbers for this case should be $A<B$ due to the same reasons mentioned in the previous example.

3. In both examples 3 and 4 , the order by the proposed method is consistent with other methods as illustrated in Table 1.

4. The ranking result for example 5 like the ranking order from D. Das method [16]. This result explains that the proposed approach works well.

5. Example 6 is presented to explain the case of ranking three different types of intuitionistic fuzzy numbers.

\subsection{Application of the Proposed Method in MADM Problem}

The multiple attribute decision-making problems under fuzzy environment have been studied extensively by many authors. In this section, we will focus on the personnel selection problem, which were presented by both Mahdavi and Deng-Feng Li [15] [30] [31]. Also, the problem was solved using value and ambiguity indexes in [31]. We develop a new algorithm to solve the personnel selection problem in the case of hybrid data types such as interval numbers, type-1 fuzzy numbers and IFNs.

Suppose that a software company desires to hire a system analyst [31]. After preliminary screening, three candidates' alternatives $A_{1}, A_{2}$ and $A_{3}$ remain for further evaluation. The decisionmaking committee assesses the three candidates. The decision makers consider five benefit criteria to evaluate these candidates, including, emotional steadiness $\left(\mathrm{C}_{1}\right)$, oral communication skill $\left(\mathrm{C}_{2}\right)$, personality $\left(\mathrm{C}_{3}\right)$, experience $\left(\mathrm{C}_{4}\right)$, and self-confidence $\left(\mathrm{C}_{5}\right)$. 
The evaluations for these criteria vary between interval numbers, type-1 fuzzy numbers and intuitionistic fuzzy numbers. The assessment for $\mathrm{C}_{1}$ is represented by triangular fuzzy numbers TFNs. The criterion $C_{2}$ is evaluated using intervals numbers INs. The assessment for the criterion $\mathrm{C}_{3}$ can be represented by Gaussian fuzzy numbers GFNs. The triangular intuitionistic fuzzy numbers TIFNs are used for $\mathrm{C}_{4}$ and $\mathrm{C}_{5}$ criteria. The evaluation values are given in Table (2) by the decision makers. The crisp weight $w_{j}$ is assigned to each criterion such that $w_{j} \in[0,1]$ and $\sum_{j=1}^{n} w_{j}=1$.

Table 2: The evaluation values of the three candidates under all criteria

\begin{tabular}{|c|c|c|l|l|l|}
\hline & $\mathrm{C}_{1}$ & $\mathrm{C}_{2}$ & \multicolumn{1}{|c|}{$\mathrm{C}_{3}$} & \multicolumn{1}{c|}{$\mathrm{C}_{4}$} & $\mathrm{C}_{5}$ \\
\hline $\mathrm{A}_{1}$ & $(5.7,7.7,9.3)$ & {$[5,9]$} & $(7.7 ; 0.7)$ & {$[(8.33,9.67,10) ; 0.6,0.4]$} & {$[(3,5,7) ; 0.6,0.3]$} \\
\hline $\mathrm{A}_{2}$ & $(6.3,8.3,9.7)$ & {$[9,10]$} & $(9.7 ; 0.12)$ & {$[(8,9,10) ; 0.6,0.3]$} & {$[(7,9,10) ; 0.6,0.2]$} \\
\hline $\mathrm{A}_{3}$ & $(6.3,8,9)$ & {$[7,10]$} & $(9 ; 0.46)$ & {$[(6,8,9) ; 0.6,0.2]$} & {$[(6.3,8.3,9.7) ; 0.7,0.2]$} \\
\hline
\end{tabular}

We propose the following steps to solve this problem as follows:

Step 1: The SFNs are obtained using author approach for the type-1 fuzzy numbers as in Table 2 for criteria $\left(\mathrm{C}_{1}\right)$ and $\left(\mathrm{C}_{3}\right)$ [3]. Also, the author method is applied to transform IFNs to SFNs for criteria $\left(\mathrm{C}_{4}\right)$ and $\left(\mathrm{C}_{5}\right)$ [4]. The new decision matrix is obtained as in Table 3.

Table 3: The evaluation values of decision table using SFNs

\begin{tabular}{|c|c|c|c|c|c|}
\hline & $\mathrm{C}_{1}$ & $\mathrm{C}_{2}$ & $\mathrm{C}_{3}$ & $\mathrm{C}_{4}$ & $\mathrm{C}_{5}$ \\
\hline $\mathrm{A}_{1}$ & $\begin{array}{l}(5.82,6.82,8.4, \\
9.2)\end{array}$ & {$[5,9]$} & $\begin{array}{l}(6.194,6.9,8.5, \\
9.122)\end{array}$ & $\begin{array}{l}(8.591,9.35,9.75, \\
9.937)\end{array}$ & $\begin{array}{l}(3.344,4.53,5.47, \\
6.656)\end{array}$ \\
\hline $\mathrm{A}_{2}$ & $\begin{array}{l}(6.42,7.42, \quad 8.92, \\
9.62)\end{array}$ & {$[9,10]$} & $\begin{array}{l}(9.424, \quad 9.55, \\
9.85,9.972)\end{array}$ & $\begin{array}{l}(8.147,8.74,9.26 \text {, } \\
9.853)\end{array}$ & $\begin{array}{l}(7.239,8.46,9.27, \\
9.88)\end{array}$ \\
\hline $\mathrm{A}_{3}$ & $\begin{array}{l}(6.39,7.24,8.45, \\
8.95)\end{array}$ & {$[7,10]$} & $\begin{array}{l}(7.979, \quad 8.46, \\
9.54,9.987)\end{array}$ & $\begin{array}{l}(6.239,7.46,8.27, \\
8.88)\end{array}$ & $\begin{array}{l}(6.525,7.72, \quad 8.71, \\
9.546)\end{array}$ \\
\hline
\end{tabular}

Step 2: The normalized SFNs are calculated using (21) and normalized interval numbers are obtained using (22). The results are displayed in Table 4.

\section{Definition 4.1:}

Let $r_{i j}$ is the normalized evaluation value for the $\mathrm{j}^{\text {th }}$ benefit criteria and two cases can be defined for it. In the case of SFN $s_{i j}=\left(s_{i j 1}, s_{i j 2}, s_{i j 3}, s_{i j 4}\right)$ is defined as

$$
r_{i j}=\left[\frac{s_{i j 1}}{\bar{s}_{j 4}}, \frac{s_{i j 2}}{\bar{s}_{j 4}}, \frac{s_{i j 3}}{\bar{s}_{j 4}}, \frac{s_{i j 4}}{\bar{s}_{j 4}}\right]
$$

where $\bar{s}_{j 4}=\max _{\mathrm{i}}\left\{\mathrm{s}_{\mathrm{ij} 4} \mid \mathrm{i}=1,2, \ldots \ldots, \mathrm{m}\right\}, \mathrm{j}=1,2, \ldots \ldots, \mathrm{n}$. In the case of interval number $\mathrm{IN}_{\mathrm{ij}}=$ $\left[\mathrm{t}_{\mathrm{ij}}^{\mathrm{L}}, \mathrm{t}_{\mathrm{ij}}^{\mathrm{R}}\right]$ is defined as the following

$$
r_{i j}=\left[\frac{t_{i j}^{L}}{\bar{t}_{j}^{R}}, \frac{t_{i j}^{R}}{\bar{t}_{j}^{R}}\right]
$$

Where $\bar{t}_{j}^{R}=\max _{i}\left\{t_{i j}^{R} \mid i=1,2, \ldots \ldots, m\right\}, j=1,2, \ldots \ldots, n$. 
Table 4: The normalized evaluation values of decision table

\begin{tabular}{|c|c|c|c|c|c|}
\hline & $\mathrm{C}_{1}$ & $\mathrm{C}_{2}$ & $\mathrm{C}_{3}$ & $\mathrm{C}_{4}$ & $\mathrm{C}_{5}$ \\
\hline $\mathrm{A}_{1}$ & $\begin{array}{l}(0.6,0.71,0.87, \\
0.96)\end{array}$ & {$[0.5,0.9]$} & $\begin{array}{l}(0.62, \quad 0.69, \\
0.85,0.91)\end{array}$ & $(0.86,0.94,0.98,1)$ & $\begin{array}{lll}(0.34, & 0.46, & 0.55, \\
0.67) & \end{array}$ \\
\hline $\mathrm{A}_{2}$ & $\begin{array}{ll}(0.67, & 0.77, \\
0.93,1) & \\
\end{array}$ & {$[0.9,1]$} & $\begin{array}{cc}0.94, & 0.96, \\
0.99,1) & \\
\end{array}$ & $\begin{array}{ccc}(0.82, & 0.88, & 0.93, \\
0.99) & & \end{array}$ & $\begin{array}{l}(0.73,0.86,0.94, \\
1)\end{array}$ \\
\hline $\mathrm{A}_{3}$ & $\begin{array}{l}(0.66,0.75, \\
0.88,0.93)\end{array}$ & {$[0.7,1]$} & $\begin{array}{cc}(0.8, & 0.85, \\
0.96,1) & \\
\end{array}$ & $\begin{array}{lll}(0.63, & 0.75, & 0.83, \\
0.89) & & \\
\end{array}$ & $\begin{array}{l}(0.66,0.78,0.88, \\
0.97)\end{array}$ \\
\hline
\end{tabular}

Step 3: Let $\mathrm{w}_{1}=0.14, \mathrm{w}_{2}=0.3, \mathrm{w}_{3}=0.12, \mathrm{w}_{4}=0.3$ and $\mathrm{w}_{5}=0.14$ are weights of attributes. The weighted normalized SFNs are obtained using (23) and the weighted normalized interval numbers are calculated using (24). The results shown in Table 5.

\section{Definition 4.2:}

Let $\mathrm{wr}_{\mathrm{ij}}$ is the weighted normalized evaluation value for the $j^{\text {th }}$ benefit criteria and we define two types of it. In the case of SFN is defined as

$$
w r_{i j}=\left[\bar{s}_{i j 1} \times w_{j}, \bar{s}_{i j 2} \times w_{j}, \bar{s}_{i j 3} \times w_{j}, \bar{s}_{i j 4} \times w_{j}\right]
$$

Where $w_{j}$ is the weight value for the $\mathrm{j}^{\text {th }}$ criteria such that $\mathrm{j}=1,2, \ldots, \mathrm{n}$. and $\overline{\mathrm{s}}_{\mathrm{ij}}=$ $\left[\overline{\mathrm{s}}_{\mathrm{ij} 1}, \overline{\mathrm{s}}_{\mathrm{ij2}}, \overline{\mathrm{s}}_{\mathrm{ij} 3}, \overline{\mathrm{s}}_{\mathrm{ij} 4}\right]$ is a normalized SFN.

In the case of interval number IN, the $w r_{i j}$ is defined as

$$
w r_{i j}=\left[\bar{t}_{\mathrm{ij}}^{\mathrm{L}} \times \mathrm{w}_{\mathrm{j}}, \overline{\mathrm{t}}_{\mathrm{ij}}^{\mathrm{R}} \times \mathrm{w}_{\mathrm{j}}\right] .
$$

Where $w_{j}$ is the weight value for thej ${ }^{\text {th }}$ criteria and $\bar{t}_{i j}=\left[\bar{t}_{i j}, \bar{t}_{i j}^{R}\right]$ is a normalized IN.

\begin{tabular}{|c|c|c|c|c|c|}
\hline & $\mathrm{C}_{1}$ & $\mathrm{C}_{2}$ & $\mathrm{C}_{3}$ & $\mathrm{C}_{4}$ & $\mathrm{C}_{5}$ \\
\hline$\overline{A_{1}}$ & $\begin{array}{l}(0.084,0.099, \\
0.122,0.134)\end{array}$ & $\begin{array}{l}{[0.15} \\
0.27]\end{array}$ & $\begin{array}{l}(0.074, \quad 0.0828, \\
0.102,0.109)\end{array}$ & $\begin{array}{ll}(0.258, & 0.282, \\
0.294,0.3) & \\
\end{array}$ & $\begin{array}{l}(0.048, \quad 0.064, \\
0.077,0.094)\end{array}$ \\
\hline$\overline{A_{2}}$ & $\begin{array}{l}(0.094,0.108,0.13, \\
0.14)\end{array}$ & {$[0.27,0.3]$} & $\begin{array}{ll}(0.113, & 0.115, \\
0.119,0.12) & \end{array}$ & $\begin{array}{l}(0.246, \quad 0.264, \\
0.279,0.297)\end{array}$ & $\begin{array}{l}(0.102, \quad 0.12, \\
0.132,0.14)\end{array}$ \\
\hline $\mathrm{A}_{3}$ & $\begin{array}{l}(0.092,0.105 \\
0.123,0.13)\end{array}$ & {$[0.21,0.3]$} & $\begin{array}{cc}(0.096, & 0.102, \\
0.115,0.12) & \\
\end{array}$ & $\begin{array}{l}(0.189, \quad 0.225, \\
0.249,0.267)\end{array}$ & $\begin{array}{l}(0.092, \quad 0.109, \\
0.123,0.136)\end{array}$ \\
\hline
\end{tabular}

Table 5: The weighted normalized evaluation values of decision table

Step 4: we use (25) and (26) to create the aggregation values of weighted normalized SFNs for three alternatives and the results shown in Table 6.

\section{Definition 4.3:}

Let $d s_{i}$ is an aggregation decision values of alternatives $A_{i}$ where $i=1,2, \ldots \ldots, m$ are obtained as

$$
d s_{i}=\sum_{j=1}^{n} w r_{i j}
$$


where $\mathrm{ds}_{\mathrm{i}}(\mathrm{i}=1,2, \ldots \ldots, \mathrm{m})$ are SFNs and $\mathrm{wr}_{\mathrm{ij}}$ is the weighted normalized evaluation value for the $j^{\text {th }}$ benefit criteria. This operation is defined between SFNs and INs as the following

$$
\mathrm{T}+\mathrm{S}=\left(\overline{\overline{\mathrm{s}}}_{1}, \overline{\overline{\mathrm{S}}}_{2}, \overline{\overline{\mathrm{S}}}_{3}, \overline{\overline{\mathrm{S}}}_{4}\right)
$$

such that $S$ is a shadowed fuzzy number SFN, $\overline{\overline{\mathrm{s}}}_{1}=\left(\mathrm{s}_{1}+\mathrm{t}_{\mathrm{L}}\right), \overline{\overline{\mathrm{s}}}_{2}=\left(\mathrm{s}_{2}+\mathrm{t}_{\mathrm{L}}\right), \overline{\overline{\mathrm{s}}}_{3}=\left(\mathrm{s}_{3}+\mathrm{t}_{\mathrm{R}}\right)$, $\overline{\bar{s}}_{4}=\left(\mathrm{s}_{4}+\mathrm{t}_{\mathrm{R}}\right)$ and $\mathrm{T}=\left[\mathrm{t}_{\mathrm{L}}, \mathrm{t}_{\mathrm{R}}\right]$ is an IN.

Table 6: The aggregation values of weighted normalized SFNs

\begin{tabular}{|l|l|}
\hline $\mathrm{A}_{1}$ & $(0.614,0.679,0.865,0.907)$ \\
\hline $\mathrm{A}_{2}$ & $(0.825,0.877,0.96,0.997)$ \\
\hline $\mathrm{A}_{3}$ & $(0.68,0.751,0.911,0.953)$ \\
\hline
\end{tabular}

Step 5: finally, we use the proposed approach to rank SFNs resulting from step 4. The rank values for alternatives $A_{1}, A_{2}$ and $A_{3}$ are $R_{A_{1}}=1.0552, R_{A_{2}}=1.3218$ and $R_{A_{3}}=1.1445$ with $\lambda=0.5$. The order of the three alternatives is $A_{2}>A_{3}>A_{1}$.

\subsection{Comparison Analysis of the Result}

Based on the previous results of the MADM problem, the following remarks are found:

In Mahdavi et al. approach, the ranking of three alternatives is $A_{2}>A_{3}>A_{1}$ which it is the same result of the new approach [30]. In Mahdavi method, the MADM problem is presented with the type-1 triangular fuzzy numbers and orders alternatives using similarity values to ideal solution.

In Deng-Feng Li et al. method, the ranking of three alternatives is $A_{3}>A_{1}>A_{2}$ with the weight $\lambda \in[0,0.793]$ [31]. This weight represents the decision maker's preference information. In the case of $\lambda \in(0.793,1]$, the order of three alternatives is $A_{1}>A_{3}>A_{2}$.

In Deng-Feng Li approach, the data inputs of MADM problem are represented by IFNs and the value-index and the ambiguity-index of IFNs are used to rank IFNs. According to Deng-Feng Li et al. method, if ratings of the alternatives on the attributes are reduced to type-1 triangular fuzzy numbers then the ranking order is $A_{2}>A_{3}>A_{1}$ [15] [31]. This result like the ranking order from the proposed method.

\subsection{Discussion}

Previous ranking approaches of fuzzy numbers with only one type of them (type-1 or higher type). These techniques were difficult to apply to complex decision-making problems that contain different types of fuzzy numbers. In the new approach, we unified the different types of fuzzy numbers using shadowed fuzzy numbers and preserve uncertainty characteristics of fuzzy numbers at the same time.

The new approach is more flexible to rank fuzzy numbers with different membership functions than previous methods. 


\section{CONCLUSION}

This paper is proposed a new approach to rank SFNs. This method is applied to order fuzzy numbers from type- 1 and higher type which transforms different types of fuzzy numbers to SFNs. The new ranking approach induces the rank values which integrates the value and the ambiguity of SFN. Also, it weighted an ambiguity value using the decision maker's attitude value. In the case of equal rank values, the fuzziness values are used to rank SFNs. The new algorithm is applied for different examples of ranking type-1 fuzzy numbers FNs and intuitionistic fuzzy numbers IFNs. The ranking results of the proposed method are compared with previous ranking approaches for type-1 FNs and IFNs. Also, the new algorithm is applied to solve a hybrid multiattribute decision making problem where SFNs are used to unify the uncertain types of linguistic terms. The new method of ranking is applied to rank alternatives.

The new algorithm is more efficient and more flexible than previous methods which solved the same problem with one type of linguistic terms.

The future work will focus on verifying the usefulness of the new approach with other multicriteria techniques. Also, we can study more applications of the new method with more decisionmaking problems.

\section{REFERENCES}

[1] Krassimir T. Atanassov, (1986) "Intuitionistic fuzzy sets", Fuzzy Sets and Systems Vol. 20, Issue (1), pp.87-96.

[2] Witold Pedrycz,(1998) "Shadowed Sets: Representing and Processing Fuzzy Sets", IEEE Transactions on systems, man, and cybernetics-part B: Cybernetics, Vol. 28, No. I.

[3] Mohamed A. H. EI_Hawy, Hesham A. Hassan, Hesham A. Hefny, Khaled T. Wassif , (2015) " An Improved Fuzzy Number Approximation using Shadowed Sets" , International Journal of Computer Applications (0975 - 8887), Vol. 118 , No.25, pp. 9-15.

[4] Mohamed A. H. EI_Hawy, Hesham A. Hassan, Hesham A. Hefny, Khaled T. Wassif , (2015)"A Proposed Shadowed Intuitionistic Fuzzy Numbers ",Computer Engineering \& Systems (ICCES), 10th, IEEE.

[5] Shyi-Ming Chen, Kata Sanguansat, (2011) "Analyzing fuzzy risk based on a new fuzzy ranking method between generalized fuzzy numbers", Expert Systems with Applications, Vol. 38, Issue 3, pp. 2163-2171.

[6] A.S.A. Bakar,D.Mohamad and N.H. Sulaiman, (2010) "Ranking fuzzy numbers using similarity measure with centroid", IEEE International Conference on Science and Social Research, pp.58-63.

[7] Chen, S., Chen, S.,(2007), "Fuzzy risk analysis based on the ranking of generalized trapezoidal fuzzy numbers.", Applied Intelligence Vol. 26, Issue 1.

[8] S.M. Chen and K. Sanguansat,(2011) "Analyzing fuzzy risk based on a new fuzzy ranking method between generalized fuzzy numbers", Expert System with Applications, Vol. 38, Issue 3, pp. $2163-$ 2171.

[9] Shi-jay chen \& shyi-mingchen, (2003) "a new method for handling multicriteria fuzzy decisionmaking problems using fn-iowa operators", Cybernetics and Systems, Vol. 34, Issue 2.

[10] L.H. Chen and H.W. Lu, (2002) "The preference order of fuzzy numbers", Computers \& Mathematics with Applications, Vol. 44, Issues 10-11, pp. 1455-1465.

[11] A.S.A. Bakar, D. Mohamad and N.H. Sulaiman, (2012) "Distance -based ranking fuzzy numbers", Advances in Computational Mathematics and Its Applications, Vol. 1, No. 3, pp.146-150.

[12] Shyi-Ming Chen, Jim-Ho Chen, (2009) "Fuzzy risk analysis based on ranking generalized fuzzy numbers with different heights and different spreads", Expert Systems with Applications, Vol.36, Issue 3, Part 2, pp. 6833-6842.

[13] Ahmad Syafadhli Abu Bakar, Alexander Gegov, (2014) "Ranking of Fuzzy Numbers Based on Centroid Point and Spread", Journal of Intelligent \& Fuzzy Systems, vol. 27, no. 3, pp. 1179-1186. 
International Journal of Computer Science \& Information Technology (IJCSIT) Vol 12, No 6, December 2020

[14] RituparnaChutia, BijitChutia, (2017) "A new method of ranking parametric form of fuzzy numbers using value and ambiguity", Applied Soft Computing,Vol. 52, pp. 1154-1168.

[15] Deng-Feng Li,(2010) "A ratio ranking method of triangular intuitionistic fuzzy numbers and its application to MADM problems", Computers \& Mathematics with Applications ,Vol. 60, Issue 6, pp. 1557-1570.

[16] P. K. De and D. Das, (2012) "Ranking of trapezoidal intuitionistic fuzzy numbers", 12th International Conference on Intelligent Systems Design and Applications (ISDA), Kochi, pp.184-188.

[17] Zhong-Xing Wang, Jian Li, (2009) "The Method for Ranking Fuzzy Numbers Based on the Approximate Degree and the Fuzziness", Sixth International Conference on Fuzzy Systems and Knowledge Discovery, IEEE.

[18] L. A. Zadeh, (1965) "Fuzzy sets." Information and Control, 8(3), pp.338-353.

[19] A. Kaufmann, M.M. Gupta,( 1985) "Introduction to Fuzzy Arithmetic Theory and Applications", Van Nostrand Reinhold, New York.

[20] George. J. Klir, Bo. Yuan, (1995) "Fuzzy Sets and Fuzzy Logic Theory and Applications", Prentice Hall press.

[21] Krassimir T. Atanassov,(1999) "Intuitionistic Fuzzy Sets. Theory and Applications", Physica-Verlag, Heidelberg New York.

[22] P.Grzegorzewski, (2003) " Distances and orderings in a family of intuitionistic fuzzy numbers",.In: EUSFLAT Conf., pp. 223-227.

[23] M. Kumar and S.P. Yadav, (2012) "Analyzing Fuzzy System Reliability Using Arithmetic Operations on Different Types of Intuitionistic Fuzzy Numbers" K. Deep et al. (Eds.): Proceedings of the International Conference on SocProS 2011, AISC 130, pp. 725-736. Springer India.

[24] Witold Pedrycz, (2009) "From Fuzzy Sets to Shadowed Sets: Interpretation and Computing", international journal of intelligent systems, Vol. 24, pp. 48-61.

[25] Yiyu Yao, Shu Wang, XiaofeiDeng,(2017) "Constructing shadowed sets and three-way approximations of fuzzy sets “, Information Sciences, Vol. 412-413, pp. 132-153.

[26] OlgierdHryniewicz,(2006) "An Evaluation of the Reliability of Complex Systems Using Shadowed Sets and Fuzzy Lifetime Data", International Journal of Automation and Computing, Vol. 2 ,pp. 145150.

[27] George J. Klir, Mark 1. Wierman,(1999) "Uncertainty -Based Information Elements of Generalized Information Theory" Springer-Verlag Berlin Heidelberg GmbH.

[28] HoomanTahayori, Alireza Sadeghian, Witold Pedrycz, (2013) "Induction of Shadowed Sets Based on the Gradual Grade of Fuzziness", Fuzzy Systems, IEEE Transactions on , vo1.21, no.5, pp.937-949.

[29] M. Delgado, M.A. Vila, W. Voxman, (1998)"On a canonical representation of fuzzy numbers", Fuzzy Sets and Systems, Vol. 93, Issue 1, pp. 125-135.

[30] Iraj Mahdavi, Nezam Mahdavi-Amiri, Armaghan Heidarzade, Rahele Nourifar,(2008 )“Designing a model of fuzzy TOPSIS in multiple criteria decision making", Applied Mathematics and Computation,Vol. 206, Issue 2, pp. 607-617.

[31] Deng Feng Li, Jiang Xia Nan \& Mao Jun Zhang ,(2010)” A Ranking Method of Triangular Intuitionistic Fuzzy Numbers and Application to Decision Making”, International Journal of Computational Intelligence Systems, Vol. 3, Issue 5, pp. 522-530. 